\title{
Multiple Orientation Relationships Among Nanocrystals of Manganese Oxides
}

Lew Rabenberg and Lionel Vayssières

Texas Materials Institute, University of Texas, Austin, TX 78712 USA

In a series of experiments[1,2] aimed at preparing anisotropic nanoparticles of transition metal oxides, we have produced nanorods of manganite $(\gamma-\mathrm{MnOOH}$, monoclinic, space group P2 $1 / \mathrm{a}$, with a $=0.5304 \mathrm{~nm}, \mathrm{~b}=0.5277 \mathrm{~nm}, \mathrm{c}=0.5304 \mathrm{~nm}$, and $\beta=11438^{\circ}$ ) that nucleate and grow on octahedral hausmannite $\left(\mathrm{Mn}_{3} \mathrm{O}_{4}\right.$, space group $\mathrm{I}_{1} / \mathrm{amd}$, and $\left.\mathrm{a}=0.5762 \mathrm{~nm}, \mathrm{c}=0.9470 \mathrm{~nm}\right)$ crystals, as well as octahedral hausmannite crystals that nucleate and grow on manganite nanorods. We show that, even though it is possible to induce the nucleation of one onto the other, there seems to be no consistently observed crystallographic relationship between them. Hausmannite and manganite are both naturally occurring minerals, and they also may occur within the cathode materials of Li ion manganese oxide batteries, where the irreversible formation of these two phases is believed to contribute to the decrease in performance.

In our experiments, controlled aqueous disproportionation reactions of $\mathrm{Mn}$ (II) salts and complexes were carried out to generate $\mathrm{Mn}$ (III) and $\mathrm{Mn}$ (II) ions in solutions at mild temperatures. Initially, precipitation of $\mathrm{Mn}_{3} \mathrm{O}_{4}$ occurs in the form of octahedral crystals attached to any surface. This reaction depletes the $\mathrm{Mn}$ (II) ions near the surface, and the remaining $\mathrm{Mn}$ (III) ions then precipitate as $\gamma$ - MnOOH. Its heteronucleation onto $\mathrm{Mn}_{3} \mathrm{O}_{4}$ surfaces leads to nanorods and nanowires. Far from the solid interfaces, where the concentration of $\mathrm{Mn}$ (II) ions remains high, the manganite rods serve as supports for further hausmannite precipitation. Samples for transmission electron microscopy and diffraction were prepared by carefully scraping the nanoparticulate thin film, collecting the nanoparticles in methanol, then evaporating the methanol on a lacey carbon support film.Samples were observed in a Jeol 2010 TEM; the high resolution pole piece of this instrument provides a point resolution of $0.19 \mathrm{~nm}$, but restricts specimen tilt to about. \pm 15 degrees.

The upper figure shows a typical image of a manganite nanorod supporting octahedral hausmannite crystals. The corresponding diffraction pattern has been included as an insert. The orientation relationship for this particular instance is determined to be: $(\overline{1} 01)_{m} / /(011)_{h} ;[121]_{m} \approx\left[111_{h}\right]$ (rotated $1.2^{\circ}$ about $\left.(\overline{1} 01)_{m}\right)$ The lower figure shows a nanorod/octahedron pair for which the interface is edge-on, allowing direct determination of the orientation relationship and the interface planes: $(11 \overline{1})_{m} / /(\overline{1} 01)_{h}$. Based on these and similar specimens, 10 such orientation relationships were obtained; no two were the same.

The fact that these clean, well-facetted crystals adopt no reproducible orientation relationship when in contact with each other is consistent with the idea that these nanocrystals do not need a crystalline template for heterogeneous nucleation. They can be induced to form at almost any surface.

\section{References}

L. Vayssières, L. Rabenberg, and A. Manthiram, Nano Letters 2, 1393 (2002)

L. Vayssières, Int. J. Nanotechnol. 1, In Press, (2003) 


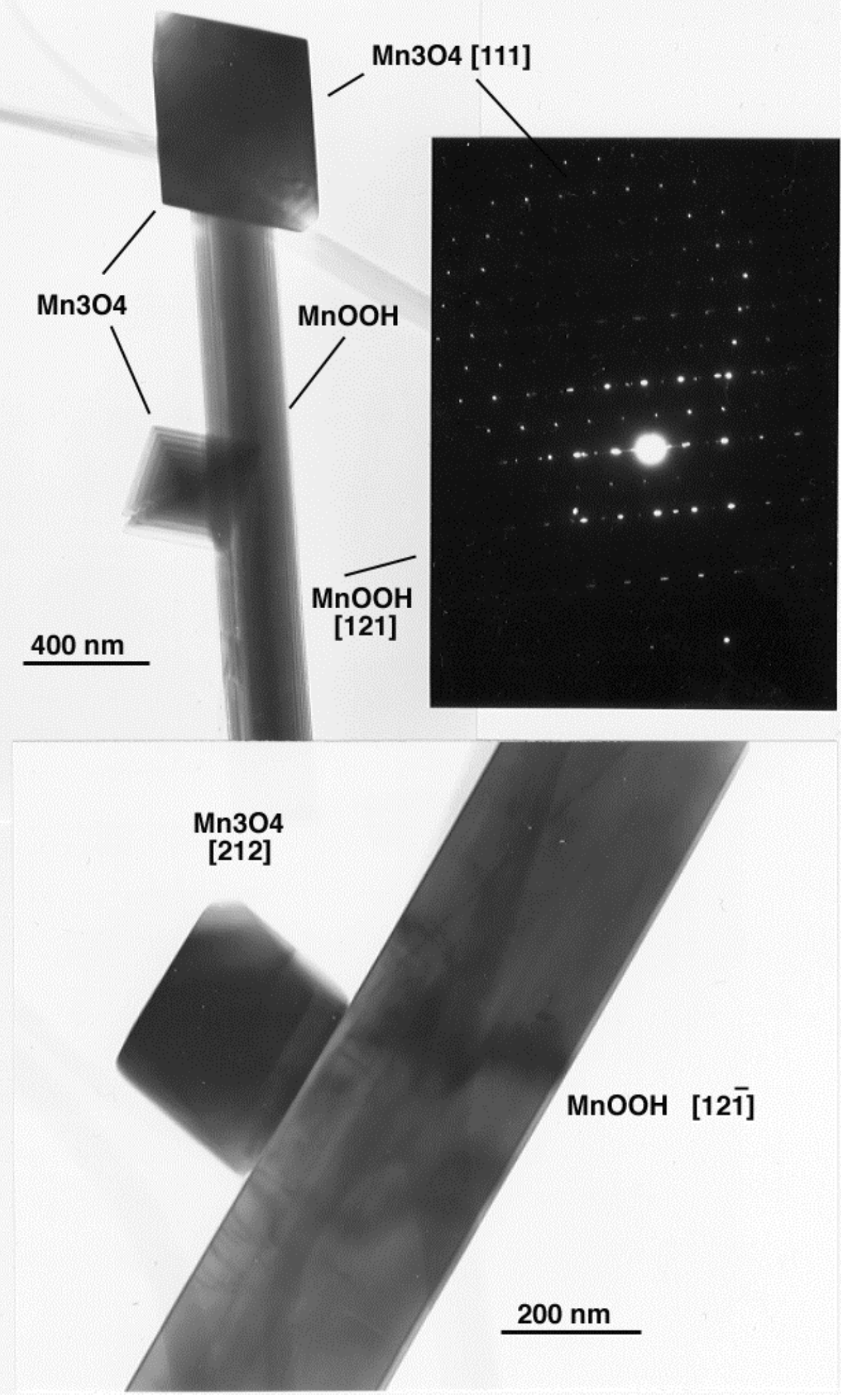

